* Mestrando em Direito da Sociedade da Informação pelo Centro Universitário das Faculdades Metropolitanas Unidas (FMU). Pós-graduado (lato sensu) em Direito e Processo do Trabalho pela Universidade Cândido Mendes (UCAM). Advogado. E-mail: rsmsoares@gmail. com.

** Pós-doutor em Direito pela Universidade de Sevilla (Espanha). Doutor em Direito pela Faculdade de Direito da Universidade de São Paulo (USP). Livre-docente pela Faculdade de Direito da Universidade de São Paulo (USP). Professor Titular do Centro Universitário do Distrito Federal (UDF). Professor da Faculdade de Direito da Universidade Presbiteriana Mackenzie (UPM). Professor do Centro Universitário das Faculdades Metropolitanas Unidas (FMU). Advogado. E-mail: gustavofbg@yahoo. com.

\section{Homologação de Sentença Arbitral Estrangeira: Reflexos da CONVENÇÃo de Nova IORQUE}

Homologation of Foreign Arbitral AwARDS: REFLECTIONS OF THE NEW YORK CONVENTION

\section{Roger Moreira Soares* Gustavo Filipe Barbosa Garcia**}

Como citar: SOARES, Rogerio Moreira; GARCIA, Gustavo Filipe Barbosa. Homologação de sentença arbitral estrangeira: reflexos da Convenção de Nova Iorque. Scientia Iuris, Londrina, v. 21, n. 1, p.87-124, mar. 2017. DOI: $10.5433 / 2178-8189.2017 v 21 \mathrm{n} 1 \mathrm{p} 87$. ISSN: $2178-8189$

Resumo: O presente estudo analisa os fundamentos e a obrigatoriedade de homologação da sentença arbitral estrangeira pelo Poder Judiciário nacional, com o fim de produzir efeitos no sistema jurídico interno, em comparação com o tratamento previsto para a sentença arbitral nacional. A arbitragem é forma alternativa de solução de conflitos que cada vez mais ganha espaço no âmbito empresarial. No plano internacional, a arbitragem tem como norma jurídica de destaque a Convenção de Nova Iorque, de 1958, incorporada ao ordenamento jurídico nacional pelo Decreto 4.311/2002. Essa norma estabelece as diretrizes 
para o reconhecimento de sentenças arbitrais estrangeiras, respeitando a soberania de cada Estado signatário, pois prevê que a sua execução deve ocorrer em conformidade com as regras de procedimento do território no qual a decisão arbitral é invocada.

Palavras-chave: Arbitragem. Sentença arbitral. Homologação. Convenção de Nova Iorque.

Abstract: This study examines the Brazilian Judiciary's requirements for the recognition of foreign arbitral awards, which result is the functioning of their legal effects in the domestic legal system. Therefore, this research compares and analyzes the Brazilian legal system's treatment of these foreign decisions with domestic awards. Nevertheless, it is without question that arbitration is an alternative form of dispute resolution with its use being especially important to the private sector. Internationally, the New York Convention of 1958 is the legislative standard for arbitration awards and the Decree 4.311/2002 incorporated it into the Brazilian legal system. Moreover, this norm establishes guidelines for the recognition of foreign and non-domestic arbitral awards, thus, respecting the sovereignty of each signatory State; however, the execution of these foreign awards have to be in accordance with the invoked country's rules of procedure. 
Keywords: Arbitration. Arbitral award. Homologation. New York Convention. 


\section{INTRODUÇÃO}

O presente estudo tem como objetivo analisar a exigência de homologação da sentença arbitral estrangeira pelo Superior Tribunal de Justiça, sob o enfoque da Convenção de Nova Iorque, principalmente quanto ao disposto em seu artigo III, ao vedar a imposição de condições substancialmente mais onerosas, em comparação com o procedimento previsto para o reconhecimento ou a execução de sentença arbitral doméstica, diante do cotejo das normas em vigor no Brasil.

Este trabalho examina os motivos pelos quais a utilização dos meios alternativos de solução de conflito tem se acentuado na sociedade globalizada, sendo o principal deles a crise do modelo exclusivamente estatal de pacificação das controvérsias, uma vez que o processo formal perante o Poder Judiciário se tornou, em certas hipóteses, custoso, demorado e rígido, sem atender às peculiaridades dos casos que são apresentados pelas partes.

Procurando afastar as dificuldades apresentadas pelo modelo tradicional de solução de conflito, ou seja, de jurisdição estatal, os particulares têm se utilizado de soluções alternativas, como a conciliação, a mediação e a arbitragem, objetivando a pacificação das controvérsias por meio de formas menos burocráticas, mais ágeis e técnicas.

Nesse contexto, a arbitragem se destaca tanto no âmbito nacional quanto internacional. Os valores envolvidos em disputais arbitrais normalmente são expressivos e a nacionalidade das partes na disputa é muitas vezes diversificada, podendo versar sobre interesses de empresas transnacionais.

A Convenção de Nova Iorque, considerada um avanço no desenvolvimento do comércio internacional, é aqui examinada sob o 
enfoque de ter uniformizado, em âmbito internacional, os procedimentos de reconhecimento das decisões arbitrais, dando maior segurança às relações empresariais e civis entre pessoas e entes de países distintos. O conhecimento claro e prévio das regras de composição dos conflitos permitiu que a economia global se aperfeiçoasse, de modo que a Convenção de Nova Iorque é considerada essencial ao início dos desdobramentos da globalização, como se observa na doutrina de Arnoldo Wald (2008, p. 13-23).

Procura-se, ainda, apresentar a distinção entre sentenças arbitrais domésticas, estrangeiras e internacionais, bem como indicar, com base em ordenamentos jurídicos de certos países, a possibilidade de existência de sentenças arbitrais com mais de uma nacionalidade, denominadas plurinacionais. Trata-se de situação que pode ser observada quando um determinado ordenamento jurídico estabelece como regra para caracterização da nacionalidade da decisão arbitral o critério ius solis (territorial, onde a sentença for proferida), enquanto outro ordenamento se vale de critério diverso. A distinção se faz necessária justamente em razão da necessidade de homologação da sentença arbitral estrangeira para que possa ser executada no Brasil.

Por fim, este artigo analisa a exigência de homologação da sentença arbitral estrangeira para que seja conferida natureza de título executivo no ordenamento jurídico nacional, traçando um paralelo com os requisitos para a execução da sentença arbitral doméstica, em consonância com a legislação nacional e a Convenção de Nova Iorque. Objetiva-se, com isso, apresentar os fundamentos favoráveis e contrários à necessidade de homologação pelo Superior Tribunal de Justiça, bem como a conclusão a respeito do tema. 


\section{CRISE DAATUAÇÃO EXCLUSIVA DO ESTADO NA SOLUÇÃO DOS CONFLITOS}

O Estado atraiu para si a prerrogativa de solucionar os conflitos na sociedade, afastando a autotutela, o que impede os interessados de fazerem uso de suas próprias razões, com o intuito de impedir o estado de violência entre as pessoas, evitando a prevalência da lei do mais forte. Surge, assim, a atuação estatal na solução dos conflitos, conforme expõem Antonio Carlos de Araújo Cintra, Ada Pellegrini Grinover e Cândido Rangel Dinamarco (1995, p. 20-21):

Hoje, se entre duas pessoas há um conflito, caracterizado por uma das causas de insatisfação descritas acima (resistência de outrem ou veto jurídico à satisfação voluntária), em princípio o direito impõe que, se se quiser pôr fim a essa situação, seja chamado o Estado-juiz, o qual virá dizer qual a vontade do ordenamento jurídico para o caso concreto (declaração) e, se for o caso, fazer com que as coisas se disponham, na realidade prática, conforme essa vontade (execução). Nem sempre foi assim, contudo. Nas fases primitivas da civilização dos povos, inexistia um Estado suficientemente forte para superar os ímpetos individualistas dos homens e impor o direito acima da vontade dos particulares: por isso, não só inexistia um órgão estatal que, com soberania e autoridade, garantisse o cumprimento do direito, como ainda não havia sequer as leis (normas gerais e abstratas impostas pelo Estado aos particulares). Assim, quem pretendesse alguma coisa que outrem o impedisse de obter haveria de, com sua própria força e na medida dela, tratar de conseguir, por si mesmo, a satisfação de sua pretensão [...] A esse regime chama-se autotutela (ou autodefesa) e 
hoje, encarando-a do ponto-de-vista da cultura do século XX, é fácil ver como era precária e aleatória, pois não garantia a justiça, mas a vitória do mais forte, mais astuto ou mais ousado sobre o mais fraco ou mais tímido.

Ainda quanto ao tema, Humberto Theodoro Júnior (2003, p. 29-30) ressalta que:

Primitivamente, o Estado era fraco e limitava-se a definir os direitos. Competia aos próprios titulares dos direitos reconhecidos pelos órgãos estatais defendelos e realiza-los com os meios de que dispunham. Eram os tempos da justiça privada ou justiça pelas próprias mãos, que, naturalmente, era imperfeita e incapaz de gerar a paz social desejada por todos. Com o fortalecimento do Estado e com o aperfeiçoamento do verdadeiro Estado de Direito, a justiça provada, já desacreditada por sua impotência, foi substituída pela Justiça Pública ou Justiça Oficial. O Estado moderno, então, assumiu para si o encargo e o monopólio de definir o direito concretamente aplicável diante das situações litigiosas, bem como o de realizar esse mesmo direito, se a parte recalcitrante recursar-se a cumprir espontaneamente o comando concreto da lei.

Entretanto, o Estado, no caso, o Poder Judiciário, não acompanhou o crescimento dos litígios que lhe são apresentados, e a exclusividade na solução dos conflitos passou a ser vista como ausência de justiça, ao trazer mais insegurança do que paz social.

Além de não acompanhar o volume das demandas, o poder jurisdicional estatal recebe a crítica de que nem sempre tem condições de pacificar adequadamente os conflitos, pois muitas vezes apenas insere determinados fatos em normas pré-existentes, sem observar as 
peculiaridades das questões submetidas a julgamento, transferindo para a lei a responsabilidade da decisão proferida no caso concreto. A respeito do tema, conforme expõem Fabiana Marion Spengler e Jose Luis Bolzan de Morais (2007, p. 314):

Todavia, tratar o conflito judicialmente significa recorrer ao magistrado e atribuir a ele o poder de dizer quem ganha e quem perde a demanda. É nesse sentido a afirmativa de que "quando se vai ao juiz se perde a face," uma vez que, imbuído do poder contratual que todos os cidadãos atribuem ao Estado, sendo por ele empossado, o magistrado regula os conflitos graças à monopolização legítima da força. O principal problema da magistratura é que ela decide litígios que lhe são alheios, sem sentir os outros do conflito, encaixando-o num modelo normativo, sem ouvir/ sentir as partes. "Para os juízes, o outro não existe, sempre decidem a partir de si mesmos, de seus egos enfermos. Decidem sem responsabilidade, porque projetam a responsabilidade na norma. Decidem conflitos sem relacionar-se com os outros. As decisões dos juízes são sem rosto". Nestes termos, os juízes crêem que sua função é administrar justiça e que a realizam, quando decidem, a partir de um conceito, simultaneamente, metafísico e determinista, que não leva em consideração, salvo raras exceções, o que as partes sentem como o justo no litígio que vivem. A tal ponto que, em alguns casos, a distribuição de justiça termina sendo uma violência para com uma das partes. Quando um juiz se preocupa em comparar se seu conceito abstrato de justiça corresponde às expectativas do que é justo para as partes?

Ainda no que tange a essa questão, segundo ressalta Marco Aurélio Gumieri Valério (2010, p. 61): 
A velocidade com que os acordos são fechados, as mercadorias circulam e a riqueza é transferida exige que eventuais conflitos sejam solucionados em tempo hábil, impondo a preferência por um método de resolução de controvérsias especializado e informal. Não é raro verificar que a tutela jurisdicional tardia, ainda que a decisão prolatada seja favorável à parte demandante, cause a ela dano irreparável, tornando inalcançável o ideal de justiça.

Quando da análise da atual crise funcional do Estado, caracterizam-na justamente como a "[...] perda de exclusividade sentida pelos órgãos incumbidos do desempenho de funções estatais, aos quais são atribuídas tarefas que lhes são inerentes [...]" (STRECK; MORAIS, 2004, p. 147), acrescentando que se observa:

[...] além de uma mudança no perfil clássico das funções estatais produzida pela transformação mesma da instituição estatal, a fragilização do Estado em suas diversas expressões quando perde concorrencialmente diante de outros setores privados, marginais, nacionais, locais, internacionais, etc. - a sua capacidade de decidir vinculativamente a respeito da lei, sua execução e da resolução de conflitos. (STRECK; MORAIS, 2004, p. 147).

A crise do modelo exclusivamente estatal, em certos casos considerado ineficaz e injusto pelos jurisdicionados, abriu espaço para a procura cada vez mais acentuada por meios diferenciados de solução dos conflitos, deixando-se de depender exclusivamente do Estado para a pacificação social. 


\section{FORMAS ALTERNATIVAS DE SOLUÇÃO DE CONFLITOS E A CONVENÇÃO DE NOVA IORQUE}

O contexto anteriormente apresentado torna nítida a relevância dos chamados meios alternativos de solução dos conflitos na atualidade.

Sustentam que a solução alternativa do conflito reconduz às partes a responsabilidade pela composição do litígio, bem como retira o autoritarismo dos atos decisórios e valoriza a autonomia de vontade:

Esse novo modelo de composição dos conflitos possui base no direito fraterno, centrado na criação de regras de compartilhamento e de convivência mútua que vão além dos litígios judiciais, determinando formas de inclusão de proteção dos direitos fundamentais. Existem outros mecanismos de tratamento das demandas, podendo-se citar a conciliação, a arbitragem e a mediação. Tratam-se de elementos que possuem como ponto comum o fato de serem diferentes, porém não estranhos à jurisdição, operando na busca da "face" perdida dos litigantes numa relação de cooperação pactuada e convencionada, definindo uma "justiça de proximidade e, sobretudo, uma filosofia de justiça do tipo restaurativo que envolve modelos de composição e gestão do conflito menos autoritariamente decisórios" (SPENGLER; MORAIS, 2007, p. 315).

Entende-se como solução alternativa do conflito a pacificação da controvérsia por meio diverso da intervenção estatal, afastando do Estado a exclusividade das atividades voltadas à paz social. Podem ser mencionadas, nesse sentido, a conciliação, a mediação e a arbitragem.

Segundo as lições de Jean Robert, a arbitragem é entendida como 
a "instituição de justiça privada, graças à qual os litígios são subtraídos das jurisdições de Direito Comum, para ser resolvidos por indivíduos revestidos, pela circunstância, da missão de julgar" (ROBERT apud PARRA, 1990, p. 223).

Jorge Barrientos Parra (1990, p. 223-224) afirma que a arbitragem se assenta na seguinte tríade: existência de lide entre duas ou mais pessoas físicas ou jurídicas de direito público ou privado; que os litigantes indiquem contratualmente um terceiro alheio à lide para resolver a questão, devendo este observar os procedimentos estabelecidos no compromisso arbitral e a legislação aplicável; e a existência do caráter vinculante da sentença arbitral para as partes a ela submetidas, com força executória nos tribunais judiciais.

Trazendo as características da arbitragem e diferenciando-a da mediação, Hildebrando Accioly, Paulo Borba Casella Geraldo e Eulalio do Nascimento e Silva (2012, p. 1.191) expõem que:

As principais características da arbitragem são: a) o acordo de vontades das partes para a fixação do objeto do litígio e o pedido de sua solução a um ou mais árbitros; b) a livre escolha destes; c) a obrigatoriedade da decisão. Distingue-se da mediação em que esta última oferece o caráter de simples conselho, enquanto a primeira se apresenta, em seu resultado, como sentença definitiva, que deve ser obedecida: o mediador é, por conseguinte, um conselheiro, ao passo que o árbitro é um juiz.

A negociação difere da mediação, pois não há naquela a presença de um terceiro, deixando exclusivamente às partes a responsabilidade pela composição, que solucionam o conflito sem a intervenção de pessoas alheias aos interesses envolvidos. 
Entre os meios alternativos de solução de controvérsias, a arbitragem tem se destacado como forma célere, adequada e especializada de pacificação de conflitos, principalmente no âmbito empresarial e internacional. A arbitragem tem se difundido de modo crescente, inclusive em face da adequação à solução de certos interesses em litígio, principalmente pela possibilidade de escolha de árbitros especializados pelas partes.

Como importante norma de Direito Internacional, a Convenção sobre o Reconhecimento e a Execução de Sentenças Arbitrais Estrangeiras, denominada Convenção de Nova Iorque, foi aprovada em 10 de junho de 1958 pelas Nações Unidas.

Após a Segunda Guerra Mundial, a necessidade de um novo instrumento voltado às sentenças arbitrais estrangeiras surgiu devido à ineficácia da Convenção de Genebra, de 1927, notadamente em face do baixo número de ratificações desse instrumento internacional.

Segundo expõe Arnoldo Wald (2008, p. 21), a Convenção de Nova Iorque permitiu o avanço do comércio internacional, por trazer maior segurança nas formas privadas de solução de conflitos, afirmando tratar-se de um primeiro passo para a globalização:

É um tratado pioneiro por várias razões. Efetivamente, como instrumento de homogeneização legislativa, permitiu a circulação internacional das decisões arbitrais, que deixou de encontrar os obstáculos existentes no passado. Podemos, até, afirmar que se trata de um primeiro passo para a globalização da economia e do direito, que ocorreria algumas décadas depois, mas que a Convenção respeitou as peculiaridades nacionais, equilibrando, assim, os interesses eventualmente conflitantes. Finalmente, constituiu uma forma de contratualização e de 
privatização do direito, ao permitir soluções consensuais decorrentes da autonomia da vontade das partes, independentemente do funcionamento da Justiça Estatal, mas sem desrespeito à mesma.

Frisa-se ainda que a Convenção de Nova Iorque surgiu após a Segunda Guerra Mundial, na fase de reconstrução da Europa, no início da Guerra Fria, com o objetivo de intensificar o comércio entre Estados de formação, cultura e ideologia diferentes. Os países em desenvolvimento buscavam a sua restruturação e o crescimento não por simples ajuda dos demais Estados considerados desenvolvidos, mas pelo comércio (WALD, 2008, p. 19).

Apesar do surgimento da Convenção de Nova Iorque em 1958, somente em 2002 o Brasil a promulgou, o que pode ser justificado por anterior posicionamento contrário a seu respeito, manifestado em diversos pareceres do então consultor jurídico do Itamaraty, Hildebrando Accioly (ARAUJO, 2008, p. 46). Entretanto, apesar da tardia ratificação do referido tratado internacional, pode-se dizer que a aceitação das previsões da Convenção de Nova Iorque ocorreu de forma tácita pela Lei ${ }^{\circ}$ 9.307, de 23 de setembro de 1996 (Lei de Arbitragem), conforme explica Arnoldo Wald (2008, p. 17):

A Convenção inspirou as novas leis nacionais elaboradas posteriormente, tendo havido modificações legislativas na maioria dos países entre 1980 e 2000. Assim, no Brasil, a Lei 9.307/96 inspirou-se na Convenção de Nova Iorque, em vários dos seus aspectos, e até a aprimorou. Como o Brasil somente aderiu à Convenção em 2002, chegou-se a afirmar que, anteriormente, tinha havido uma espécie de ratificação tácita e de incorporação do seu texto pela legislação nacional brasileira, constituindo "uma 
espécie de adesão por osmose".

Embora já integrada ao ordenamento jurídico pátrio, a Convenção de Nova Iorque, de certa forma, acabou não trazendo profundas transformações ao sistema jurídico brasileiro, visto que a Lei de Arbitragem, de 1996, em diversos aspectos, foi elaborada sob a sua influência, adotando algumas de suas previsões.

\section{SENTENÇA ARBITRAL NACIONAL, ESTRANGEIRA, INTERNACIONAL E PLURINACIONAL}

É importante apresentar os conceitos e as características das sentenças arbitrais quanto à nacionalidade. Essa questão tem consequências quanto ao reconhecimento das decisões arbitrais no ordenamento jurídico como títulos executivos.

O ordenamento pátrio, por meio da Lei de Arbitragem (Lei ${ }^{\circ}$ 9.307, de 23 de setembro de 1996), valeu-se de referência de certa forma singela, ao adotar o critério territorial, ou seja, o chamado ius solis. Desse modo, ao ser proferida a sentença arbitral no território nacional, a sentença é considerada doméstica (artigo 34, parágrafo único, da Lei de Arbitragem, a contrario sensu). Ao se utilizar esse critério, pouco importa se as partes litigantes sejam estrangeiras, se o direito ou o contrato discutido extrapole os limites territoriais do País, se o árbitro eleito seja estrangeiro ou se o tribunal arbitral possua sede em outro país, com representação no território nacional. Sendo proferida no Brasil, a sentença arbitral é considerada nacional.

Carlos Augusto da Silveira Lobo (2006, p. 69), ao questionar o método adotado pela legislação pátria para caracterizar como nacional 
a sentença arbitral, expõe a seguinte hipótese:

Os que entendem que a sentença é proferida no lugar em que os árbitros a subscrevem esbarram logo de início numa dificuldade insuperável. Suponhamos um tribunal composto de três árbitros, um deles residindo e exercendo atividades no Japão, outro na Inglaterra e outro no Brasil. Suponhamos ainda que os três tenham discutido e aprovado os termos da sentença sem se reunirem em um só local, pois utilizaram meios eletrônicos para se comunicarem (internet ou videoconferência). Essas suposições não decorrem da imaginação do autor, pois são de frequente ocorrência na prática da arbitragem internacional. Então perguntamos: É razoável exigir que os três se desloquem apenas para assinarem a sentença arbitral no lugar designado pela convenção de arbitragem consoante o inciso IV do artigo 10 da Lei $\mathrm{n}^{\circ} 9.307$ ? Será infringido esse dispositivo, se cada um dos árbitros permanecer no lugar em que se acha, sendo a sentença remetida para cada um deles e devolvida, depois de assinada, por correio especial? Nesse caso, a sentença será estrangeira por conter duas assinaturas apostas no exterior, ou será considerada doméstica porque foi assinada no Brasil pelo árbitro que aqui tem residência? A questão terá de ser resolvida por critérios arbitrários e de conteúdo fortuito, como, por exemplo: a sentença foi proferida no país em que foi aposta a primeira assinatura, ou no país em que se encontrava o último árbitro que a assinou, ou no país onde se encontrava o árbitro presidente; ou, se tiver uma das assinaturas aposta no Brasil, será doméstica.

A situação acima pode se tornar cada vez mais comum na sociedade da informação, em que a tecnologia e os meios de comunicação possibilitam o estreitamento das diversas relações jurídicas. Ao se 
buscar a imparcialidade no julgamento pela arbitragem, em que a tradição e a formação dos árbitros poderiam dar margem a um prévio juízo de convencimento, seria possível pensar em eleger árbitros com nacionalidades e situados em localidades diversas, podendo ser, por exemplo, um de certa nacionalidade, residente no Brasil, outro de nacionalidade distinta, residente na China, e um terceiro de nacionalidade diversa, residente na Alemanha, todos proferindo os seus votos no julgamento arbitral. Em situações assim, é possível que a sentença arbitral possa ser considerada brasileira, em razão de um dos seus julgadores se situar no Brasil, podendo, entretanto, apresentar outras nacionalidades, conforme parâmetros adotados por outros países para distinguir sentença arbitral doméstica de estrangeira. Desse modo, a falta de uniformização quanto ao tema merece certa crítica.

As situações expostas mostram a fragilidade do critério meramente territorial adotado. Entretanto, esse entendimento é o que prevalece no sistema jurídico brasileiro, como reconhece a jurisprudência, a exemplo da decisão proferida no Recurso Especial n ${ }^{\circ} 1.231 .554 / \mathrm{RJ}$, da $3^{\text {a }}$ Turma do Superior Tribunal de Justiça, de 24 de maio de 2011, o qual teve como relatora a Ministra Nancy Andrighi.

Nesse julgamento foi decidido que "[...] a determinação da internacionalidade ou não de sentença arbitral, para fins de reconhecimento, ficou ao alvedrio das legislações nacionais [...]", fazendo-se referência ao disposto no art. I da Convenção de Nova Iorque, promulgada pelo Brasil por meio do Decreto 4.311/2002. Conclui-se que no ordenamento jurídico nacional foi adotada como elemento de conexão a territorialidade. Desse modo, o "[...] lugar onde foi proferida a sentença arbitral' não suscita maiores dúvidas, ante a clareza das disposições contidas na Lei da Arbitragem" (WALD, 2008, p. 18). 
Esclareça-se que o referido julgado deu provimento a recurso interposto, decidindo que a sentença deve ser considerada doméstica, por ter sido proferida em território nacional. Houve, assim, a reforma do acórdão proferido no Agravo de Instrumento $n^{\circ} 0062827$ 33.2009.8.19.0000, oriundo da $12^{\mathrm{a}}$ Câmara Cível do Tribunal de Justiça do Estado do Rio de Janeiro, tendo como relator o Desembargador Antônio Iloízio Barros Bastos, de 23 de fevereiro de 2010, no qual foi adotado o entendimento de que o fato de as partes terem escolhido um Tribunal Arbitral com sede em Paris (Tribunal Internacional de Arbitragem da Câmara de Comércio Internacional) teve o condão de indicar que desejaram a solução do litigio por decisão estrangeira, bem como, apesar de proferida por árbitro nacional, este estaria vinculado e representava a entidade arbitral estrangeira, seguindo, inclusive, as suas normas específicas e próprias.

A respeito do tema, José Eduardo Carreira Alvim (2007, p. 181) expõe a disciplina básica sobre o tema na legislação nacional:

Para ser considerada estrangeira, basta que a sentença arbitral tenha sido proferida fora do território nacional, pouco importando a nacionalidade dos árbitros ou do tribunal, bem assim as regras (materiais ou procedimentais) que tenham presidido o juízo arbitral. Por isso, determina a Lei $\mathrm{n}^{\circ}$ 9.307/96, dentre os requisitos obrigatórios do compromisso, dele conste o lugar em que será proferida a sentença arbitral, pois é este o seu elemento nacionalizante ou internacionalizante. Da mesma forma, se for proferida no território brasileiro, a sentença arbitral será nacional, ainda que proferida por árbitro ou tribunal estrangeiro, segundo regras (materiais ou procedimentais) não-nacionais. $\mathrm{O}$ critério adotado foi o ius solis. 
Desse modo, no ordenamento jurídico nacional ficou definido que a sentença arbitral estrangeira é "[...] a que tenha sido proferida fora do território nacional [...]"', enquanto que, a contrario sensu, a sentença arbitral nacional é a proferida nos limites territoriais do País.

Outros métodos de identificar a nacionalidade da sentença arbitral são apontados pela doutrina, observando-se o Direito comparado. Com isso, os diversos sistemas jurídicos, cada qual com seus critérios de caracterização de sentença doméstica e estrangeira, podem acarretar o surgimento de sentenças arbitrais de nacionalidades plúrimas, conforme explica Edoardo Flávio Ricci (2004, p. 218):

Mas é possível enfrentar o tema da nacionalidade da sentença arbitral, sob outra ótica: a de sua qualificação nos diferentes sistemas de direitos. Nesse caso, constata-se que uma sentença arbitral pode ser qualificada como nacional por mais de um direito, podendo-se, então, falar de nacionalidade plúrima da sentença arbitral à semelhança da hipótese da dupla nacionalidade do cidadão. Sob o aspecto formal, a sentença arbitral é única; entretanto, verifica-se que mais de um Estado a considera como tendo sua nacionalidade, ignorando as demais nacionalidades que lhe atribuem outros Estados e, ao mesmo tempo, refutando a possibilidade de qualificala como estrangeira.

Edoardo Flávio Ricci (2004, p. 221) faz ainda referência a exemplo em que, sendo proferida em território nacional a sentença arbitral, por óbvio que terá a nacionalidade brasileira, mas também, dependendo do caso, poderá a decisão arbitral possuir a nacionalidade

1 Lei nº 9.307, de 23 de setembro de 1996 (Lei de Arbitragem), artigo 34, parágrafo único. 
da Alemanha, da Itália e da Suíça, pois os ordenamentos jurídicos desses países não se filiam à teoria territorial para definir a nacionalidade da sentença arbitral, mas adotam o critério da sede da arbitragem, que é escolhida pelas partes contratantes, ou definida pelos árbitros, no caso de ausência de manifestação das partes a respeito, como ressalta:

A sede da arbitragem não tem relação com o local em que é proferida a sentença. Trata-se, em vez, de simples localização legal da arbitragem, de livre escolha das partes ou dos árbitros. Igualmente não tem interferência o local do procedimento da arbitragem. Importante observar que tudo isso é aceito por unanimidade, não havendo discrepância de opiniões.

Assim, se a arbitragem ocorrer no Brasil, com todo o desenvolvimento do procedimento em território nacional, a sentença arbitral será doméstica para o sistema jurídico nacional. Entretanto, se constar cláusula no sentido de se eleger a sede legal da arbitragem em Milão/Itália, embora esse aspecto não gere efeitos para o sistema brasileiro, a sentença arbitral pode ser classificada de modo distinto por outro país que leve em consideração esse aspecto.

Carlos Alberto Carmona expõe o modelo jurídico francês, que adotou o conceito de sentença arbitral doméstica e sentença arbitral internacional:

Os franceses preferiram a conceituação mais etérea: é internacional, diz o art. 1.492 do Código de Processo Civil francês, a arbitragem que coloca em jogo os interesses do comércio internacional. Tal definição - disse Habscheid com precisão - é por um lado muito vasta, e por outro muito limitada: segundo o 
critério francês, seria considerada internacional uma arbitragem submetida a um órgão internacional com sede em Paris onde litigassem dois comerciantes franceses concorrentes no plano internacional; por outro lado, não seria arbitragem internacional aquela desenvolvida em Nice para solucionar disputas entre dois herdeiros de uma rica senhora inglesa, falecida na Côte D'Azur, acerca de propriedades na França, Suíça e Inglaterra. Mas se fosse o caso de definir, através da arbitragem, a liquidação de interesses comerciais da falecida, a arbitragem seria internacional (CARMONA, 2009, p. 438-439).

Explica Giovanni Bonato (2015, p. 264) que o modelo francês, para caracterizar a internacionalização da arbitragem, utiliza critério exclusivamente econômico que transcende os limites territoriais de um único país:

Impende frisar que o critério da internacionalização da arbitragem, previsto pelo CPC francês, é claramente de tipo econômico e se caracteriza pelo fato de que o litígio submetido ao árbitro tem por objeto uma operação que não se desenvolve economicamente em um só país, pois implica um movimento de recursos além das fronteiras, envolvendo o comércio transfronteiriço. Esse critério é puramente econômico, na medida em que faz abstração dos elementos jurídicos de extraneidade, como a nacionalidade, o domicílio e a residências das partes, o lugar da celebração do contrato objeto do litígio e a sede da arbitragem.

Como se observa, a sentença internacional transcende os interesses de um ordenamento jurídico e a solução a ser proferida produz efeitos perante relações comerciais mantidas além dos limites territoriais 
de um único país.

A Convenção de Nova Iorque prevê no artigo I a sua aplicação ao reconhecimento e à execução de sentenças arbitrais estrangeiras proferidas no território de um Estado que não seja aquele em que se pretenda o reconhecimento e a execução de tais sentenças, oriundas de divergências entre pessoas, sejam elas físicas ou jurídicas. Além disso, a Convenção de Nova Iorque aplica-se a sentenças arbitrais não consideradas como sentenças domésticas no Estado onde se pretenda o seu reconhecimento e a sua execução. Nesse último caso, portanto, o Estado poderia estabelecer critérios para afastar a natureza de decisão arbitral doméstica, atribuindo-lhe o caráter de sentença arbitral internacional, como ocorre no ordenamento jurídico francês, conforme mencionado anteriormente.

O caráter internacional da sentença arbitral, que considera o alcance e elementos tratados no procedimento arbitral, está previsto na Lei Modelo UNCITRAL, em seu artigo 1, item 3:

Uma arbitragem é internacional se:

a) As partes em uma convenção de arbitragem tiverem, no momento da sua conclusão, as suas sedes comerciais em diferentes Estados; ou

b) Um dos locais a seguir referidos estiver situado fora do Estado no qual as partes têm a sua sede;

(i) O local da arbitragem, se determinado na, ou de acordo com, convenção de arbitragem;

(ii) Qualquer local onde deva ser cumprida uma parte substancial das obrigações resultantes da relação comercial ou o local com o qual o objeto da disputa tenha vínculos mais estreitos; ou

(iii) As partes tiverem convencionado expressamente que o objeto da convenção de arbitragem envolve mais de um país. 
Francisco José Cahali (2014, p. 408), citando José Maria Rossani Garcez, sustenta que a legislação nacional não se preocupou em definir o que seria a arbitragem internacional, mas apresenta critérios para identificar a referida natureza:

[...] 'para diferenciar a arbitragem nacional da internacional pode-se, basicamente, utilizar o mesmo critério diferenciador entre os contratos nacionais e internacionais: nos primeiros acham-se presentes, em geral, elementos conectados a um mesmo sistema legal, as partes têm residência no mesmo Estado e este, em geral, não difere daquele em que o contrato será executado', enquanto 'nos contratos e nas arbitragens internacionais, em geral intervêm legislações em conexão com mais de um sistema legal nacional, as partes têm domicílio em países diferentes, o local da constituição da obrigação contratual ou da convenção arbitral em geral ocorre em país estranho ao domicílio de uma das partes, o local da execução do contrato, ou da realização da arbitragem, pode ser um dos países de domicílio de uma das partes ou, ainda, um terceiro país'.

Considerando as características de diversos ordenamentos, é possível que a sentença arbitral apresente, ao mesmo tempo, conforme o país, por exemplo, a nacionalidade brasileira, italiana e, ainda, para o ordenamento francês possua natureza internacional, caso a arbitragem ocorra em território nacional, mas com eleição da sede legal em alguma cidade da Itália e envolva litígio sobre comércio internacional.

\section{EFICÁCIA DA SENTENÇA ARBITRAL ESTRANGEIRA NO BRASIL E EXECUÇÃO DA SENTENÇAARBITRAL NACIONAL:}




\section{NECESSIDADE DE HOMOLOGAÇÃO DA SENTENÇA ARBITRAL ESTRANGEIRA}

De início, é importante esclarecer que há certa controvérsia doutrinária quanto ao tema: uma corrente sustenta a desnecessidade de homologação da sentença arbitral estrangeira e outra defende a sua necessidade, a fim de que possa produzir efeitos jurídicos no território nacional. Assim, passa-se a analisar essa temática, apresentando os principais argumentos de ambas as correntes.

A homologação de sentença arbitral estrangeira e a sua inserção no sistema jurídico nacional são regidas, essencialmente, pelas seguintes normas jurídicas: Constituição Federal de 1988, artigo 105, inciso I, alínea “i”; Lei no 9.307, de 23 de setembro de 1996, artigos 34 a 40 (Lei de Arbitragem); Decreto $\mathrm{n}^{\mathrm{O}} 4.311$, de 23 de julho de 2002, que promulgou a Convenção de Nova Iorque, de 10 de junho de 1958; Decreto-lei no 4.657, de 4 de setembro de 1942, artigos 15 ao 17 (Lei de Introdução às Normas do Direito Brasileiro); Lei no 13.105, de 16 de março de 2015, artigos 960 ao 965 (Código de Processo Civil de 2015); e o Regimento Interno do Superior Tribunal de Justiça, artigos 216-A ao 216-X, (artigos inclú́dos pela Emenda Regimental n ${ }^{\circ}$, de 2014, e que revogou a Resolução ${ }^{\circ}$ 9, de 4 de maio de 2005, todos do Superior Tribunal de Justiça).

A expressa previsão da necessidade de homologação da sentença arbitral estrangeira consta do artigo 35 da Lei de Arbitragem.

O Código de Processo Civil de 2015, no artigo 515, incisos VII e VIII, prevê a sentença arbitral e a sentença estrangeira homologada pelo Superior Tribunal de Justiça como títulos executivos judiciais.

O procedimento de homologação de sentença arbitral estrangeira pelo Superior Tribunal de Justiça é disciplinado nos artigos 216-A ao 
216-X do Regimento Interno do próprio STJ.

Devem ser examinadas, assim, as posições favoráveis e contrárias à necessidade de homologação da sentença arbitral estrangeira.

É importante notar que a Lei de Arbitragem, em seu artigo 34², estabelece a sua posição de norma subsidiária quanto ao reconhecimento ou execução da sentença arbitral estrangeira no Brasil, por ser aplicada na ausência de tratado internacional com eficácia no ordenamento interno.

O mesmo ocorre com o artigo 960, $\S 3^{\circ}$, do Código de Processo Civil de 2015, que remete a disciplina da homologação da sentença arbitral estrangeira a tratado ou lei especial, qual seja, a Lei de Arbitragem, que, por sua vez, como mencionado, é aplicável de forma subsidiária, devendo ser observada no caso de omissão de tratado internacional sobre a matéria.

A Lei no 9.307/1996 é diploma legal que versa exclusivamente sobre arbitragem, enquanto a Convenção de Nova Iorque trata especificamente de sentença arbitral estrangeira. O Código de Processo Civil de 2015, por seu turno, é norma processual de caráter geral, que não revoga as normas específicas.

Sustenta Luiz Antonio Scavone Júnior (2014, p. 233-234) que a necessidade de homologação da sentença arbitral estrangeira não possui fundamento no artigo 35 da Lei de Arbitragem ou no Código de Processo Civil, mas que essa exigência decorre da previsão constitucional:

Todavia, a homologação de sentenças arbitrais estrangeiras pelo STJ não decorre do art. 35 da Lei de Arbitragem ou do art. 483 do CPC, mas de dispositivo constitucional (art. 105, I, i), hierarquicamente superior aos tratados, equiparados que são às leis ordinárias. Portanto, a homologação é necessária.

2 Lei n. 9.307/96 (Lei de Arbitragem). Art. 34. A sentença arbitral estrangeira será reconhecida ou executada no Brasil de conformidade com os tratados internacionais com eficácia no ordenamento interno e, na sua ausência, estritamente de acordo com os termos desta Lei. 
A rigor, o artigo 105, inciso I, alínea "i" da Constituição Federal de 1988, incluída pela Emenda Constitucional 45/2004, prevê a competência do Superior Tribunal de Justiça para a homologação da sentença estrangeira, mas não dispõe expressamente sobre a necessidade de homologação de sentença arbitral estrangeira propriamente.

Em verdade, se a obrigatoriedade de homologação da sentença arbitral estrangeira, como exigência para produzir efeitos no Brasil, decorresse do artigo 105, inciso I, alínea "i" da Constituição Federal de 1988, que é norma hierarquicamente superior à Convenção de Nova Iorque, não teria validade nem mesmo o artigo $961, \S 5^{\circ}$, do Código de Processo Civil de 2015, ao prever que a sentença estrangeira de divórcio consensual produz efeitos no Brasil, independentemente de homologação pelo Superior Tribunal de Justiça. Pode-se concluir, assim, que a Constituição da República, no artigo 105, inciso I, alínea "i”, não prevê a obrigatoriedade da homologação, mas apenas estabelece a competência quanto à matéria.

A Convenção de Nova Iorque, em seu artigo III, dispõe que cada Estado signatário deve reconhecer as sentenças como obrigatórias e as executar em conformidade com as regras de procedimento do território no qual a sentença é invocada, embora também de acordo com as condições estabelecidas no referido diploma internacional. Ademais, determina o referido dispositivo que para fins de reconhecimento ou de execução das sentenças arbitrais às quais a Convenção de Nova Iorque se aplica não devem ser impostas condições substancialmente mais onerosas ou taxas ou cobranças mais altas do que as exigidas para o reconhecimento ou a execução de sentenças arbitrais domésticas (grifou-se). 
Ao se interpretar essa previsão, nota-se que o Estado signatário pode estabelecer os procedimentos para o reconhecimento ou a execução da sentença arbitral estrangeira, o qual pode ser um pouco mais oneroso, porém não de forma substancial; além disso, não se admite a exigência de taxas mais altas do que para o reconhecimento e a execução de sentença arbitral doméstica.

A questão é saber o que seriam condições substancialmente mais onerosas, pois a sentença arbitral doméstica, se descumprida, pode dar início ao processo judicial de execução de imediato, enquanto a sentença arbitral estrangeira precisa ser homologada pelo Superior Tribunal de Justiça. O tempo médio para isso, segundo estudos do Comitê Brasileiro de Arbitragem, em análise feita desde o início da vigência da Lei de Arbitragem, de 1996, até 2009, é de 17,4 meses até o trânsito em julgado, sem considerar eventual recurso extraordinário ao Supremo Tribunal Federal. Após o procedimento de homologação da sentença arbitral estrangeira, ela ainda estará sujeita às demais impugnações judiciais que uma sentença arbitral doméstica também pode receber.

Diferenciando a natureza da sentença judicial estrangeira da sentença arbitral estrangeira, José Carlos Magalhães (1997, p. 43) assevera que a homologação da sentença judicial estrangeira pelo Judiciário local se justifica por se tratar de ato oficial emitido por autoridade pública estrangeira, ressaltando que o artigo 181 da Constituição Federal de 1988, a fim de evitar a aplicação extraterritorial dos atos administrativos e judiciais estrangeiros no território nacional, submete-os à aprovação do Poder competente interno. Entretanto, o referido autor apresenta entendimento diverso quando se trata de sentença arbitral estrangeira:

Não é o caso do laudo arbitral, ato privado, 
proferido por pessoa ou pessoas naturais, despidas de qualquer autoridade pública e não atuando em nome de qualquer país. A sua execução, no Brasil, tem o mesmo caráter do cumprimento de contrato internacional firmado fora do país e aqui cumprido, não se cogitando de submetê-lo à prévia apreciação do Judiciário. Em caso de descumprimento, a parte interessada poderá ingressar com ação judicial, caso em que, e somente nesse caso, o Poder Judiciário, como faria com qualquer contrato, mesmo nacional, examinará sua adequação a princípios jurídicos do país (MAGALHÃES, 1997, p. 44).

De acordo com a posição acima indicada, um contrato internacional para ser executado no Brasil não necessita de homologação ou autorização do Poder Judiciário. Logo, esse mesmo contrato com a previsão de arbitragem em câmara estrangeira para dirimir conflitos também não necessitaria, após a intervenção de árbitros, de ser homologado, na atualidade, pelo Superior Tribunal de Justiça. Nesse enfoque, não haveria alteração da natureza jurídica privada do contrato, mesmo que internacional, quando submetido à arbitragem (MAGALHÃES, 1997, p. 44; SAMPAIO, 2012, p. 126).

Conforme esse entendimento, o contrato continuaria a ser o mesmo, apenas com a intervenção previamente contratada pelas partes para a solução do conflito pelo árbitro. A sentença arbitral (estrangeira) não seria algo dissociado do contrato a ser cumprido. Desse modo, se este não exige homologação pelo Poder Judiciário para ter eficácia no sistema jurídico nacional, também não deixaria de tê-la quando o árbitro, escolhido pelas partes, apresentasse a solução do conflito oriundo desse contrato (MAGALHÃES, 1997, p. 44).

Carlos Alberto Vilela Sampaio (2012, p. 126) também sustenta 
o caráter privado da sentença arbitral, assim expondo:

Trata-se indiscutivelmente de mecanismo privado, extrajudicial portanto, de solução de litígios, no qual um terceiro escolhido pelas partes por meio de um contrato profere uma decisão sobre a controvérsia havida. Naturalmente o seu resultado, o laudo arbitral, não poderia ter outra natureza que não a privada, contratual. Não foi essa a conduta adotada pelo legislador.

Como se pode notar, por ser a arbitragem uma forma alternativa de solução de conflito oriunda da vontade das partes, com caráter extrajudicial, evolvendo tão somente direitos patrimoniais disponíveis, com a pacificação feita por terceiros (árbitros) escolhidos pelas partes, segundo parte da doutrina, seria equivocada a exigência da legislação brasileira de homologação de ato jurídico desprovido de autoridade estatal, isto é, da sentença arbitral estrangeira.

A presença de ato proferido por autoridade estatal estrangeira é que demandaria a homologação pelo Poder Judiciário brasileiro, mas não um contrato particular, ainda que seguido de laudo arbitral, seja ele doméstico, estrangeiro ou internacional.

Entretanto, a doutrina majoritária, bem como a jurisprudência e a legislação brasileira indicam a natureza jurisdicional da decisão arbitral, tornando necessária a homologação quando se tratar de sentença estrangeira, tal como ocorre na jurisdição estatal.

Cândido Rangel Dinamarco e Bruno Vasconcelos Carrilho Lopes (2016, p. 23), analisando o conceito de tutela jurisdicional, esclarecem que esta não se confunde com o serviço realizado pelos juízes no exercício da função estatal, tratando-se, na verdade: 
[...] do resultado do processo em que essa função se exerce. Ela não reside na decisão judicial em si mesma como ato processual, mas nos efeitos que ela efetivamente produz fora do processo e sobre as relações entre pessoas ou entre estas e os bens da vida.

Efetivamente, o sistema jurídico nacional reconhece a natureza jurisdicional da sentença arbitral, a exemplo do artigo 42 da Lei $n^{\circ}$ 13.105, de 16 de março de 2015 (Código de Processo Civil de 2015), ao prever que as causas cíveis devem ser processadas e decididas pelo juiz nos limites de sua competência, ressalvado às partes o direito de instituir juízo arbitral, na forma da lei, bem como no artigo 485, inciso VII, ao reconhecer a competência do juízo arbitral, em detrimento do juízo estatal. O Código de Processo Civil de 2015 estabelece ainda, de forma expressa, que a sentença arbitral tem natureza de título executivo judicial (artigo 515, inciso VII).

A Lei n 9.307, de 23 de setembro de 1996 (Lei de Arbitragem) também é expressa em identificar a natureza jurisdicional do laudo arbitral, a exemplo do artigo $3^{\circ}$ (“juízo arbitral”). O artigo 14 do referido diploma legal impõe aos árbitros os mesmos impedimentos ou suspeições dos juízes, o artigo 17 equipara os árbitros aos funcionários públicos para efeitos de legislação penal e, por fim, o artigo 18 estabelece que o árbitro é juiz de fato e de direito, bem como profere sentença que não fica sujeita a recurso ao Poder Judiciário.

Tanto a legislação pátria adotou a natureza jurisdicional da arbitragem que estabeleceu, como forma de interrupção da prescrição, a instituição do procedimento arbitral (artigo $19, \S 2^{\circ}$, da Lei de Arbitragem). Ademais, o procedimento arbitral deve respeitar os 
preceitos processuais aplicáveis à jurisdição estatal, como o princípio do contraditório, a igualdade das partes, a imparcialidade dos árbitros e o livre convencimento (artigo 21, § $2^{\circ}$, da Lei $n^{\circ}$ 9.307/1996). Além disso, a sentença arbitral produz os mesmos efeitos da sentença proferida pelos órgãos do Poder Judiciário (artigo 31 da Lei de Arbitragem).

Logo, o sistema jurídico não deixa dúvidas quanto à natureza jurisdicional da sentença arbitral, ao reconhecer a jurisdição (não estatal) exercida pelos tribunais arbitrais. Observa-se, portanto, que a jurisdição não é atividade exclusiva do Estado.

Analisando a natureza jurisdicional da arbitragem, assim expõe Cândido Rangel Dinamarco (2013, p. 39):

[...] hoje é imperioso entender que a jurisdicionalidade é inerente à própria arbitragem, prescindindo das vicissitudes da legislação ou mesmo das opções do legislador. O que há de fundamental é o reconhecimento da função de pacificar pessoas mediante a realização de justiça, exercida tanto pelo juiz togado quanto pelo árbitro. [...] Assumindo enfaticamente que a jurisdição tem por escopo magno a pacificação de sujeitos conflitantes, dissipando os conflitos que os envolvem, e sendo essa a razão última pela qual o próprio Estado a exerce, não há dificuldade alguma para afirmar que também os árbitros exercem jurisdição, uma vez que sua atividade consiste precisamente em pacificar com justiça, eliminando conflitos. Não é à toa ou por acaso que a arbitragem se situa no contexto dos meios de solução de conflitos (conquanto alternativo).

É oportuna a observação de Suzana Santi Cremasco e Tiago Eler Silva (2011,p. 376), ao esclarecerem que quando se opta pela arbitragem 
não se abre mão da jurisdição, mas sim da exclusividade do Estado para a solução de conflitos:

Por outro lado, improcede, ainda, a afirmação no sentido de que ao optarem pela arbitragem, as partes renunciariam à jurisdição, aqui tomada, na sua essência, como função desempenhada por terceiros no sentido de por fim à controvérsia até então existente. Com efeito, ao firmarem a convenção arbitral as partes não renunciam à jurisdição, mas à jurisdição estatal, optando, pois, por submeter o seu conflito de interesses à jurisdição convencional.

Conforme salientam os referidos autores, embora limitada quanto às atividades de coerção, por se necessitar do Poder Judiciário quanto a elas, a arbitragem não deixa de ser caracterizada como jurisdição:

É certo, porém, que enquanto modalidade de jurisdição não judiciária que é e em face do seu caráter eminentemente privado, a jurisdição arbitral permanece limitada apenas para o exercício do iudicium, em todos os seus termos e prerrogativas, reservando-se a realização do imperium apenas ao juízo estatal. Isso ocorre na medida em que a realização do imperium pressupõe a realização de atos que implicam em expropriação forçada, ou seja, que pressupõem o uso da força (coerção), uso da força esse sim que o Estado detém em caráter de monopólio. A limitação, aqui, longe de descaracterizar o caráter jurisdicional da arbitragem, traz para ele uma limitação, isto é, uma medida, numa noção que se aproxima sobremaneira do conceito de competência (enquanto medida da jurisdição) assentado na ciência processual para a jurisdição estatal (CREMASCO; SILVA, 2011, p. 378). 
Nelson Nery Jr e Rosa Maria de Andrade Nery (2006. p. 140141), analisando a jurisdição arbitral, expõem ainda que:

5. Jurisdição e árbitro. Instituído o juízo arbitral por convenção de arbitragem celebrada entre as partes, nele o árbitro é juiz de fato e de direito (LArb 18), decide a lide substituindo a vontade das partes, e sua sentença não fica sujeita a recurso nem precisa ser homologada pelo Poder Judiciário, tendo força de coisa julgada material. Conquanto não seja juiz nomeado mediante concurso de provas e títulos, exerce jurisdição.

Ainda segundo os mencionados autores:

1. Jurisdição arbitral. A natureza jurídica da arbitragem é de jurisdição. O árbitro exerce jurisdição porque aplica o direito ao caso concreto e coloca fim à lide que existia entre as partes. A arbitragem é instrumento de pacificação social. Sua decisão é exteriorizada por meio de 'sentença', que tem qualidade de título executivo judicial (CPC 475-N IV), não havendo necessidade de ser homologada pela jurisdição estatal. A execução da sentença arbitral é aparelhada por título judicial, sendo passível de impugnação ao cumprimento de sentença com fundamento no CPC 475-L, segundo a LArb $33 \S 3^{\circ}$. (NERY JR; NERY, 2006. p. 1167).

Por fim, diversos julgados do Superior Tribunal de Justiça reconhecem o caráter jurisdicional da arbitragem, podendo ocorrer, inclusive, conflito de competência entre o juízo arbitral e juízo estatal, o que demonstra tratar-se de efetiva jurisdição. Nesse sentido, pode ser indicado, como exemplo, acórdão da Segunda Seção do Superior 
Tribunal de Justiça, quando do julgamento do Conflito de Competência $\mathrm{n}^{\circ}$ 111.230/DF, relatora ministra Nancy Andrighi, publicado no Diário da Justiça eletrônico de 03.04.2014, ao assim destacar: "A atividade desenvolvida no âmbito da arbitragem tem natureza jurisdicional, sendo possível a existência de conflito de competência entre juízo estatal e câmara arbitral".

Portanto, não se pode conceituar a jurisdição como o poder exclusivo do Estado de dizer o direito no caso concreto, mas sim como forma de solução de conflito com a finalidade de se alcançar a paz social. É justamente esse o objetivo do procedimento arbitral, o que justifica a sua natureza jurisdicional.

Logo, assim como ocorre com a sentença estatal estrangeira, exige-se a homologação pelo Superior Tribunal de Justiça também nos casos de sentença arbitral estrangeira.

\section{CONCLUSÃO}

Não mais se justifica a exclusividade do Estado na solução dos conflitos e na concretização da paz social. Mesmo porque a demora na pacificação das controvérsias pode se aproximar da própria ausência de justiça.

A crise do modelo estatal de solução judicial reforçou a presença dos meios alternativos de pacificação social. Além de se demonstrar moroso e custoso em certos casos, alega-se que o modelo estatal perdeu credibilidade quanto ao conhecimento técnico específico para se decidir determinadas demandas que são apresentadas.

A arbitragem, ao possibilitar às partes o estabelecimento do procedimento para a solução dos conflitos de interesses, bem como a 
escolha de árbitros que possuam imparcialidade e conhecimentos técnicos necessários ao julgamento da controvérsia, tem merecido cada vez maior ênfase, principalmente na esfera empresarial, tornando-se importante meio de solução de controvérsias nesse âmbito.

A Convenção de Nova Iorque serviu para ampliar o comércio internacional e incentivar os investimentos, versando sobre o reconhecimento e a execução de sentenças arbitrais estrangeiras. Consolida-se, assim, como relevante marco jurídico no processo de globalização econômica, ao trazer maior segurança e fomento às relações comerciais entre agentes e atores sociais de países distintos.

Anecessidade de homologação pelo Superior Tribunal de Justiça, notadamente em razão do tempo necessário para esse procedimento, em tese, poderia ser vista como condição substancialmente mais onerosa para o reconhecimento da sentença arbitral estrangeira, sabendo-se que a sentença arbitral doméstica não está submetida à mesma exigência. Ainda assim, prevalece o entendimento de que é necessária a homologação da sentença arbitral estrangeira, tendo em vista a sua natureza jurisdicional.

Se a sentença judicial estrangeira deve ser submetida à homologação pelo Poder Judiciário nacional para que tenha eficácia no Brasil, diferente conclusão não poderia ser aplicada à sentença arbitral estrangeira, pois ambas apresentam natureza jurisdicional.

Não se pode dar tratamento distinto a situações iguais segundo a lei. O sistema jurídico exige a homologação da sentença judicial estrangeira pelo Superior Tribunal de Justiça para que possa ser executada no Brasil, inclusive em razão da soberania nacional. Sendo assim, a mesma exigência incide quanto à sentença arbitral estrangeira. Efetivamente, embora esta não seja proferida por autoridade estatal, o árbitro também exerce jurisdição, tendo como função a pacificação do 
conflito que lhe é submetido.

Dessa forma, partindo-se da ideia de que a jurisdição, como forma de pacificação social por meio da solução do conflito, não é função exclusiva do Estado, tem-se a caracterização da sentença arbitral também como ato de natureza jurisdicional.

Portanto, entende-se que a sentença arbitral estrangeira deve se submeter aos mesmos procedimentos das sentenças judiciais estrangeiras para a produção de efeitos no território nacional, com destaque à sua homologação pelo STJ, exigência esta inerente ao sistema jurídico e que não resulta em imposição de procedimento substancialmente mais gravoso às sentenças arbitrais estrangeiras em comparação às sentenças arbitrais nacionais.

\section{REFERÊNCIAS}

ACCIOLY, Hildebrando; SILVA, Geraldo Eulalio do Nascimento; CASELLA, Paulo Borba. Manual de direito internacional público. 20. ed. São Paulo: Saraiva, 2012.

ALVIM, José Eduardo Carreira. Comentários à lei de arbitragem. Rio de Janeiro: Juruá, 2007.

ARAUJO, Nadia. A Convenção de Nova York sobre reconhecimento e execução de laudos arbitrais estrangeiros: análise das razões contrárias à sua adoção nos anos 50 do século XX. Revista de Arbitragem e Mediação, São Paulo, v. 18, p. 42-49, jul./set. 2008.

BONATO, Giovanni. A arbitragem internacional na França e a arbitragem societária na Itália: algumas reflexões comparativas com o direito brasileiro. Revista da Faculdade de Direito da Universidade Federal do Estado de Minas Gerais, Belo Horizonte, n. 66, p. 253- 
289, jan./jun. 2015.

CAHALI, Francisco José. Curso de arbitragem. 4. ed. São Paulo: RT, 2014.

CARMONA, Carlos Alberto. Arbitragem e processo: um comentário à Lei n 9.307/96. 3. ed. São Paulo: Atlas, 2009.

CINTRA, Antonio Carlos de Araújo; GRINOVER, Ada Pellegrini; DINAMARCO, Cândido Rangel. Teoria geral do processo. 11. ed. São Paulo: Malheiros, 1995.

CREMASCO, Suzana Santi e SILVA, Tiago Eler. O caráter jurisdicional da arbitragem e o precedente arbitral. Revista da Faculdade de Direito da Universidade Federal de Minas Gerais, Belo Horizonte, n. 59, p. 367-404, jul./dez. 2011.

DINAMARCO, Cândido Rangel. A arbitragem na teoria geral do processo. São Paulo: Malheiros, 2013.

DINAMARCO, Cândido Rangel; LOPES, Bruno Vasconcelos Carrilho. Teoria geral do novo processo civil. São Paulo: Malheiros, 2016.

GARCEZ, José Maria Rossani. Arbitragem internacional. In: CAHALI, Francisco José. Curso de arbitragem. 4. ed. São Paulo: RT, 2014. p. 402-418.

LOBO, Carlos Augusto da Silveira. A definição de sentença arbitral estrangeira. Revista de Arbitragem e Mediação, São Paulo, v. 3, n. 9, p. 62-71, abr./jun. 2006.

LOPEZ, Marcelo Leandro Pereira. CARVALHO, Erick Leonardo Freire. A lei de arbitragem e a Convenção de Nova Iorque à luz do 
STJ: efeitos da Emenda Constitucional n. 45. Revista CEJ, Brasília, v.17, n. 60, p. 16-28, maio/ago. 2013. Disponível em: <http://www. jf.jus.br/ojs2/index.php/revcej/article/viewFile /1694/1750>. Acesso em: 22 maio 2016.

MAGALHÃES, José Carlos. Reconhecimento e execução de laudos arbitrais estrangeiros. Revista de Informação Legislativa, Brasília, v. 34, n. 134, p. 41-50, abr./jun. 1997.

NERY JÚNIOR, Nelson e NERY, Rosa Maria de Andrade. Código de processo civil comentado e legislação extravagante. 9. ed. São Paulo: RT, 2006.

PARRA, Jorge Barrientos. Fundamentos da arbitragem no direito brasileiro e estrangeiro. Revista de Informação Legislativa, Brasília, v. 27, n. 107, p. 215-244, jul./set. 1990.

RICCI, Edoardo Flávio. Lei de arbitragem brasileira. São Paulo: RT, 2004.

ROBERT, Jean. Arbitrage civil et commercial em droit interne et international privé: suivi de formules pratiques. Paris: Dalloz, 1967. In: PARRA, Jorge Barrientos. Fundamentos da arbitragem no direito brasileiro e estrangeiro. Revista de Informação Legislativa, Brasília, v. 27, n. 107 , p. 223 , jul./set. 1990.

SAMPAIO, Carlos Alberto Vilela. Reconhecimento da sentença e do laudo arbitral estrangeiros. 2012. 175 p. Dissertação (Mestrado em Direito) - Faculdade de Direito da Universidade de São Paulo, São Paulo, 2012.

SCAVONE JR, Luiz Antonio. Manual de arbitragem. 5. ed. Rio de Janeiro: Forense, 2014. 
SPENGLER, Fabiana Marion e MORAIS, Jose Luis Bolzan de. O conflito, o monopólio estatal de seu tratamento e a construção de uma resposta consensuada: a "jurisconstrução". Revista Sequência, Florianópolis, n. 55, p. 303-326, dez. 2007.

STRECK, Lenio Luiz; MORAIS, José Luiz Bolzan de. Ciência política e teoria geral do estado. 4 ed. Porto Alegre: Livraria do Advogado, 2004.

THEODORO JÚNIOR, Humberto. Curso de direito processual civil. 40. ed. Rio de Janeiro: Forense, 2003. v. 1.

VALÉRIO, Marco Aurélio Gumieri. Homologação de sentença arbitral estrangeira. Cinco anos de reforma do judiciário. Revista de Informação Legislativa, Brasília, v. 47, n. 186, p. 61-76, abr./jun. 2010.

WALD, Arnoldo. A Convenção de Nova Iorque: o passado, o presente e o futuro. Revista de Arbitragem e Mediação, São Paulo, v. 18, p. 13-23, jul./set. 2008.

Como citar: SOARES, Rogerio Moreira; GARCIA, Gustavo Filipe Barbosa. Homologação de sentença arbitral estrangeira: reflexos da Convenção de Nova Iorque. Scientia Iuris, Londrina, v. 21, n. 1, p.87124, mar. 2017. DOI: 10.5433/2178-8189.2017v21n1p87. ISSN: $2178-$ 8189

Recebido em: 20/07/2016

Aprovado em: 21/02/2017 